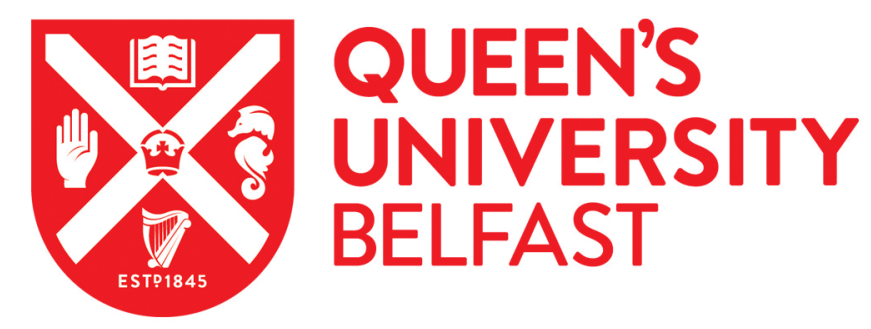

\title{
Hydrocarbon Anions in Interstellar Clouds and Circumstellar Envelopes
}

Millar, TJ., Walsh, C., Cordiner, M. A., Ni Chuimin, R., \& Herbst, E. (2007). Hydrocarbon Anions in Interstellar Clouds and Circumstellar Envelopes. Astrophysical Journal, 662(2 II), L87-L90.

Published in:

Astrophysical Journal

Queen's University Belfast - Research Portal:

Link to publication record in Queen's University Belfast Research Portal

\section{General rights}

Copyright for the publications made accessible via the Queen's University Belfast Research Portal is retained by the author(s) and / or other copyright owners and it is a condition of accessing these publications that users recognise and abide by the legal requirements associated with these rights.

Take down policy

The Research Portal is Queen's institutional repository that provides access to Queen's research output. Every effort has been made to ensure that content in the Research Portal does not infringe any person's rights, or applicable UK laws. If you discover content in the Research Portal that you believe breaches copyright or violates any law, please contact openaccess@qub.ac.uk. 


\title{
HYDROCARBON ANIONS IN INTERSTELLAR CLOUDS AND CIRCUMSTELLAR ENVELOPES
}

\author{
T. J. Millar, C. Walsh, and M. A. Cordiner \\ Astrophysics Research Centre, School of Mathematics and Physics, Queen's University Belfast, Belfast BT7 1NN, Northern Ireland; \\ Tom.Millar@qub.ac.uk, cwalsh13@qub.ac.uk, m.cordiner@qub.ac.uk \\ R. Ní CHUIMÍN \\ Jodrell Bank Centre for Astrophysics, School of Physics and Astronomy, University of Manchester, Sackville Street, Manchester \\ M60 1QD, UK; Roisin.Ni-Chuimin@manchester.ac.uk \\ AND \\ ERIC HERBST \\ Departments of Physics, Chemistry and Astronomy, Ohio State University, Columbus, OH 43210-1106; herbst@mps.ohio-state.edu \\ Received 2007 March 8; accepted 2007 May 2; published 2007 May 30
}

\begin{abstract}
The recent detection of the hydrocarbon anion $\mathrm{C}_{6} \mathrm{H}^{-}$in the interstellar medium has led us to investigate the synthesis of hydrocarbon anions in a variety of interstellar and circumstellar environments. We find that the anion/ neutral abundance ratio can be quite large, on the order of at least a few percent, once the neutral has more than five carbon atoms. Detailed modeling shows that the column densities of $\mathrm{C}_{6} \mathrm{H}^{-}$observed in IRC +10216 and TMC-1 can be reproduced. Our calculations also predict that other hydrocarbon anions, such as $\mathrm{C}_{4} \mathrm{H}^{-}$and $\mathrm{C}_{8} \mathrm{H}^{-}$, are viable candidates for detection in IRC +10216 , TMC-1, and photon-dominated regions such as the Horsehead Nebula.
\end{abstract}

Subject headings: astrochemistry — ISM: abundances — ISM: clouds — ISM: molecules — stars: carbon

\section{INTRODUCTION}

The recent detection by McCarthy et al. (2006) of $\mathrm{C}_{6} \mathrm{H}^{-}$in the carbon-rich asymptotic giant branch (AGB) star IRC +10 216 and in the cold, dense interstellar cloud TMC-1, with abundance ratios relative to $\mathrm{C}_{6} \mathrm{H}$ of $0.01-0.1$, indicates that anions may play a more significant role in interstellar physics and chemistry than heretofore believed.

The possibility that a relatively large fraction of molecular material in interstellar clouds might be in the form of anions was first suggested by Herbst (1981), who pointed out that carbon chain molecules and other radicals have large electron affinities, leading to high radiative attachment rates such as those measured by Woodin et al. (1980) with the attendant possibility of anion/neutral fractions on the order of a few percent. More recently, it has been recognized that polycyclic aromatic hydrocarbon (PAH) anions could soak up a significant fraction of the free electrons in interstellar clouds and alter the charge balance to a significant degree (Lepp \& Dalgarno 1988a), as well as providing significant heating through photodetachment of electrons in diffuse clouds (Lepp \& Dalgarno 1988b). Petrie (1996) has investigated the synthesis of $\mathrm{CN}^{-}$by the dissociative attachment of $\mathrm{MgCN}$ and $\mathrm{MgNC}$ and other mechanisms, while Petrie \& Herbst (1997) showed that $\mathrm{C}_{3} \mathrm{~N}^{-}$ could be detectable in interstellar clouds. The study of large hydrocarbon anions received some attention following the observation by Tulej et al. (1998) that absorption bands in several carbon chain anions coincided with several of the diffuse interstellar bands (DIBs). Subsequently, the formation of such species in diffuse clouds was studied by Ruffle et al. (1999), who showed, in particular, that $\mathrm{C}_{7}^{-}$was unlikely to be a source for any DIB. Millar et al. (2000) considered the formation of hydrocarbon anions containing more than six carbon atoms in the carbon-rich circumstellar envelope of IRC +10216 and showed that appreciable column densities could arise in the outer envelope.

\section{CHEMICAL MODEL}

The basic route to the formation of anions is electron radiative attachment:

$$
\mathrm{X}+e^{-} \rightarrow \mathrm{X}^{-}+h \nu
$$

which has been discussed in the context of bare carbon chains by Terzieva \& Herbst (2000). The rate coefficients of relevant processes have not been experimentally determined at low temperatures, and in this work we have used phase-state theory assuming $s$-wave attachment with radiative stabilization occurring by vibrational and electronic transitions (Terzieva \& Herbst 2000). Table 1 contains some relevant attachment rate coefficients. The calculations of rates for these and other processes will be discussed in a separate paper (E. Herbst 2007, in preparation). For $\mathrm{C}_{n} \mathrm{H}$ radicals, we find that radiative attachment occurs at the collisional rate once the number of carbon atoms is larger than five; for $\mathrm{C}_{4} \mathrm{H}$, the attachment efficiency is only around $1 \%$. Barckholtz et al. (2001) have shown experimentally that neither carbon chain anions nor hydrocarbon anions react with $\mathrm{H}_{2}$ but that they do so with $\mathrm{H}$ atoms. We have also included loss reactions of anions with $\mathrm{C}, \mathrm{C}^{+}$, $\mathrm{C}_{2} \mathrm{H}_{2}^{+}$(in IRC +10216 ), and photons, with all cation-anion rate coefficients taken to be $10^{-7} \mathrm{~cm}^{3} \mathrm{~s}^{-1}$. For the photodetachment rates, some of which are shown in Table 1, we have assumed the cross section $\sigma$ to depend on photon energy $\epsilon$ via the relation

$$
\sigma=\sigma_{0}(1-\mathrm{EA} / \epsilon)^{0.5}, \quad \epsilon \geq \mathrm{EA},
$$

where $\sigma_{0}=1.0 \times 10^{-17} \mathrm{~cm}^{2}$ and EA is the electron affinity of the neutral molecule. Relevant electron affinities have been obtained from theoretical and experimental results (E. Herbst 2007, in preparation). The UV radiation field as described by Mathis et al. (1983) has been adopted. We have extended earlier models such as that by Ruffle et al. (1999), which included $\mathrm{C}_{n}^{-}, n=7-23$, and by Millar et al. (2000), which included 
TABLE 1

Some Reactions and Rate Coefficients

\begin{tabular}{lclcc}
\hline \hline \multicolumn{1}{c}{ Reactions } & Products & \multicolumn{1}{c}{$\alpha$} & $\beta$ & $\gamma$ \\
\hline$e^{-}+\mathrm{C}_{4} \mathrm{H}$ & $\mathrm{C}_{4} \mathrm{H}^{-}$ & $2.00 \mathrm{E}-9$ & -0.5 & $\ldots$ \\
$e^{-}+\mathrm{C}_{5}$ & $\mathrm{C}_{5}^{-}$ & $3.30 \mathrm{E}-8$ & -0.5 & $\cdots$ \\
$e^{-}+\mathrm{C}_{5} \mathrm{H}$ & $\mathrm{C}_{5} \mathrm{H}^{-}$ & $9.00 \mathrm{E}-10$ & -0.5 & $\cdots$ \\
$e^{-}+\mathrm{C}_{6}$ & $\mathrm{C}_{6}^{-}$ & $1.70 \mathrm{E}-7$ & -0.5 & $\cdots$ \\
$e^{-}+\mathrm{C}_{6} \mathrm{H}$ & $\mathrm{C}_{6} \mathrm{H}^{-}$ & $6.00 \mathrm{E}-8$ & -0.5 & $\cdots$ \\
$e^{-}+\mathrm{C}_{7}$ & $\mathrm{C}_{7}^{-}$ & $5.00 \mathrm{E}-7$ & -0.5 & $\cdots$ \\
$e^{-}+\mathrm{C}_{7} \mathrm{H}$ & $\mathrm{C}_{7} \mathrm{H}^{-}$ & $2.00 \mathrm{E}-7$ & -0.5 & $\cdots$ \\
$e^{-}+\mathrm{C}_{8}$ & $\mathrm{C}_{8}^{-}$ & $1.70 \mathrm{E}-7$ & -0.5 & $\cdots$ \\
$e^{-}+\mathrm{C}_{8} \mathrm{H}$ & $\mathrm{C}_{8} \mathrm{H}^{-}$ & $6.00 \mathrm{E}-8$ & -0.5 & $\cdots$ \\
$e^{-}+\mathrm{C}_{9}$ & $\mathrm{C}_{9}^{-}$ & $5.00 \mathrm{E}-7$ & -0.5 & $\cdots$ \\
$e^{-}+\mathrm{C}_{9} \mathrm{H}$ & $\mathrm{C}_{9} \mathrm{H}^{-}$ & $2.00 \mathrm{E}-7$ & -0.5 & $\cdots$ \\
$e^{-}+\mathrm{C}_{10}$ & $\mathrm{C}_{10}^{-}$ & $1.70 \mathrm{E}-7$ & -0.5 & $\cdots$ \\
$e^{-}+\mathrm{C}_{10} \mathrm{H}$ & $\mathrm{C}_{10} \mathrm{H}^{-}$ & $6.00 \mathrm{E}-8$ & -0.5 & $\ldots$ \\
$\mathrm{C}_{4} \mathrm{H}^{-}+$photon & $\mathrm{C}_{4} \mathrm{H}+e^{-}$ & $1.80 \mathrm{E}-9$ & 0.0 & 2.0 \\
$\mathrm{C}_{5}^{-}+$photon & $\mathrm{C}_{5}+e^{-}$ & $3.00 \mathrm{E}-9$ & 0.0 & 1.5 \\
$\mathrm{C}_{5} \mathrm{H}^{-}+$photon & $\mathrm{C}_{5} \mathrm{H}+e^{-}$ & $3.70 \mathrm{E}-9$ & 0.0 & 1.5 \\
$\mathrm{C}_{6}^{-}+$photon & $\mathrm{C}_{6}+e^{-}$ & $1.30 \mathrm{E}-9$ & 0.0 & 2.0 \\
$\mathrm{C}_{6} \mathrm{H}^{-}+$photon & $\mathrm{C}_{6} \mathrm{H}+e^{-}$ & $1.50 \mathrm{E}-9$ & 0.0 & 2.0 \\
$\mathrm{C}_{7}^{-}+$photon & $\mathrm{C}_{7}+e^{-}$ & $2.40 \mathrm{E}-9$ & 0.0 & 1.5 \\
$\mathrm{C}_{7} \mathrm{H}^{-}+$photon & $\mathrm{C}_{7} \mathrm{H}+e^{-}$ & $3.00 \mathrm{E}-9$ & 0.0 & 1.5 \\
$\mathrm{C}_{8}^{-}+$photon & $\mathrm{C}_{8}+e^{-}$ & $1.10 \mathrm{E}-9$ & 0.0 & 2.0 \\
$\mathrm{C}_{8} \mathrm{H}^{-}+$photon & $\mathrm{C}_{8} \mathrm{H}+e^{-}$ & $1.40 \mathrm{E}-9$ & 0.0 & 2.0 \\
$\mathrm{C}_{9}^{-}+$photon & $\mathrm{C}_{9}+e^{-}$ & $1.60 \mathrm{E}-9$ & 0.0 & 2.0 \\
$\mathrm{C}_{9} \mathrm{H}^{-}+$photon & $\mathrm{C}_{9} \mathrm{H}+e^{-}$ & $2.00 \mathrm{E}-9$ & 0.0 & 2.0 \\
$\mathrm{C}_{10}^{-}+$photon & $\mathrm{C}_{10}+e^{-}$ & $1.00 \mathrm{E}-9$ & 0.0 & 2.0 \\
$\mathrm{C}_{10} \mathrm{H}^{-}+$photon & $\mathrm{C}_{10} \mathrm{H}+e^{-}$ & $1.40 \mathrm{E}-9$ & 0.0 & 2.0 \\
\hline
\end{tabular}

NoTE.-For electron attachment, $k=\alpha(T / 300)^{\beta}$ in units of $\mathrm{cm}^{3} \mathrm{~s}^{-1}$; for photodetachment, $k=\alpha e^{-\gamma A_{V}}$ in units of $\mathrm{s}^{-1}$.

$\mathrm{C}_{n} \mathrm{H}^{-}, n=7-23$, down to anions containing four carbon atoms following the determination of the microwave spectrum of $\mathrm{C}_{4} \mathrm{H}^{-}$by Gupta et al. (2007).

In addition to the reactions discussed above, we have included in the circumstellar envelope (CSE) and photon-dominated region (PDR) models radiative association between carbon chain anions and neutrals leading to carbon chains of up to 23 carbon atoms (Millar et al. 2000), while in the dark cloud models we have included reactions between anions and $\mathrm{O}$ atoms, with a rate coefficient of $10^{-10} \mathrm{~cm}^{3} \mathrm{~s}^{-1}$, unless specifically measured (Eichelberger et al. 2002).

\section{RESULTS}

\subsection{Circumstellar Envelope}

We model the carbon-rich AGB star IRC + 10216 using the numerical model developed by Millar et al. (2000) and Millar (2003). They modeled the formation of anions with more than six carbon atoms and showed that the anion radial distribution could extend beyond $10^{17} \mathrm{~cm}$, and relative to their neutral analogs, abundance ratios approaching 0.1 (for $\mathrm{C}_{7}^{-}$, for example) could be achieved. Some results of our present calculation, in which we have extended our species down to $\mathrm{C}_{4} \mathrm{H}^{-}$, are shown in Table 2 and Figure 1. Our results show that column densities of $1.0 \times 10^{13} \mathrm{~cm}^{-2}$ for $\mathrm{C}_{4} \mathrm{H}^{-}$to $2.3 \times 10^{13} \mathrm{~cm}^{-2}$ for $\mathrm{C}_{10} \mathrm{H}^{-}$are achievable, with anion-to-neutral column density ratios of 0.008 for $\mathrm{C}_{4} \mathrm{H}$ to around $0.3-0.4$ for $\mathrm{C}_{6} \mathrm{H}, \mathrm{C}_{8} \mathrm{H}$, and $\mathrm{C}_{10} \mathrm{H}$. Note that although the electron attachment efficiency for $\mathrm{C}_{4} \mathrm{H}$ is only around $1 \%$ that of $\mathrm{C}_{6} \mathrm{H}$ and $\mathrm{C}_{8} \mathrm{H}, \mathrm{C}_{4} \mathrm{H}^{-}$has a relatively large column density since $\mathrm{C}_{4} \mathrm{H}$ is more abundant. Both $\mathrm{C}_{4} \mathrm{H}^{-}$and $\mathrm{C}_{8} \mathrm{H}^{-}$are candidates for detection in IRC +10216 . In the region interior to a radial distance of $8 \times 10^{16} \mathrm{~cm}$, the main loss of anions occurs through reaction with $\mathrm{H}$ atoms, while mutual neutralization with $\mathrm{C}^{+}$dominates in $(1.8-13) \times 10^{17} \mathrm{~cm}$. Elsewhere, photodetachment is the major loss route.

McCarthy et al. (2006) measured a $\mathrm{C}_{6} \mathrm{H}^{-}$column density of
TABLE 2

IRC +10216 Hydrocarbon Anion Chemistry Model Results

\begin{tabular}{|c|c|c|c|c|}
\hline Species & $\begin{array}{l}\text { Column Density } \\
\left(\mathrm{cm}^{-2}\right)\end{array}$ & $\begin{array}{l}\text { Peak Abundance } \\
\text { relative to } \mathrm{H}_{2}\end{array}$ & $\begin{array}{l}\text { Obs. Column } \\
\text { Density } \\
\left(\mathrm{cm}^{-2}\right)\end{array}$ & Refs. \\
\hline $\mathrm{C}_{4} \mathrm{H} \ldots \ldots \ldots$ & $1.3 \times 10^{15}$ & $2.1 \times 10^{-6}$ & $(2-9) \times 10^{15}$ & $1,2,3,4$ \\
\hline $\mathrm{C}_{4} \mathrm{H}^{-} \ldots \ldots$ & $1.0 \times 10^{13}$ & $1.3 \times 10^{-8}$ & $\ldots$ & \\
\hline $\mathrm{C}_{6} \mathrm{H} \ldots \ldots$. & $5.7 \times 10^{14}$ & $1.2 \times 10^{-6}$ & $(0.3-3) \times 10^{14}$ & 3,4 \\
\hline $\mathrm{C}_{6} \mathrm{H}^{-} \ldots \ldots$ & $1.7 \times 10^{14}$ & $2.6 \times 10^{-7}$ & $3 \times 10^{12}$ & 5 \\
\hline $\mathrm{C}_{8} \mathrm{H} \ldots \ldots \ldots$ & $2.1 \times 10^{14}$ & $4.4 \times 10^{-7}$ & $5 \times 10^{12}$ & 4 \\
\hline $\mathrm{C}_{8}^{0} \mathrm{H}^{-} \ldots \ldots$ & $5.8 \times 10^{13}$ & $1.4 \times 10^{-7}$ & $\ldots$ & \\
\hline $\mathrm{C}_{10} \mathrm{H} \ldots \ldots$ & $5.8 \times 10^{13}$ & $1.3 \times 10^{-7}$ & $\ldots$ & \\
\hline $\mathrm{C}_{10} \mathrm{H}^{-} \ldots \ldots$ & $2.3 \times 10^{13}$ & $8.3 \times 10^{-8}$ & $\ldots$ & \\
\hline
\end{tabular}

$3 \times 10^{12} \mathrm{~cm}^{-2}$, approximately 60 times less than is produced in our model. Although the column density is overproduced, it is important to note that the column densities of the large hydrocarbon chains are very sensitive to the initial abundance of acetylene adopted in the model. This results from the fact that the most efficient method of growth is via the addition of $\mathrm{C}_{2}$ units. For example, if the initial abundance of $\mathrm{C}_{2} \mathrm{H}_{2}$ is reduced by 5 , the column density of $\mathrm{C}_{6} \mathrm{H}$ is reduced by about 45 , and that of $\mathrm{C}_{10} \mathrm{H}$ by 100 . The anion column densities are not affected as much, typically reducing by about an order of magnitude, since less acetylene also leads to a reduction in the abundances of $\mathrm{H}$ atoms and $\mathrm{C}^{+}$in the envelope. The observed anion-to-neutral ratio is $0.01-0.1$, where the range is due to the range of reported $\mathrm{C}_{6} \mathrm{H}$ column densities (Kawaguchi et al. 1995; Guélin et al. 1997) but is in reasonable agreement with the calculated value of 0.3 , given the uncertainties in the rates of anion formation (by radiative electron attachment) and destruction.

Finally, we note that the anion abundances can be greater than that of free electrons in the region around $5 \times 10^{16} \mathrm{~cm}$. This reflects the efficiency of carbon chain growth and electron attachment. A similar result is found in dark cloud models when PAHs are included (Lepp \& Dalgarno 1988a).

\subsection{Dark Clouds}

Here we adopt parameters applicable to the cold dust cloud TMC-1 $\left[n\left(\mathrm{H}_{2}\right)=2 \times 10^{4} \mathrm{~cm}^{-3}, T=10 \mathrm{~K}, A_{V}=10 \mathrm{mag}\right]$ and perform quasi-time-dependent modeling. The initial ele-

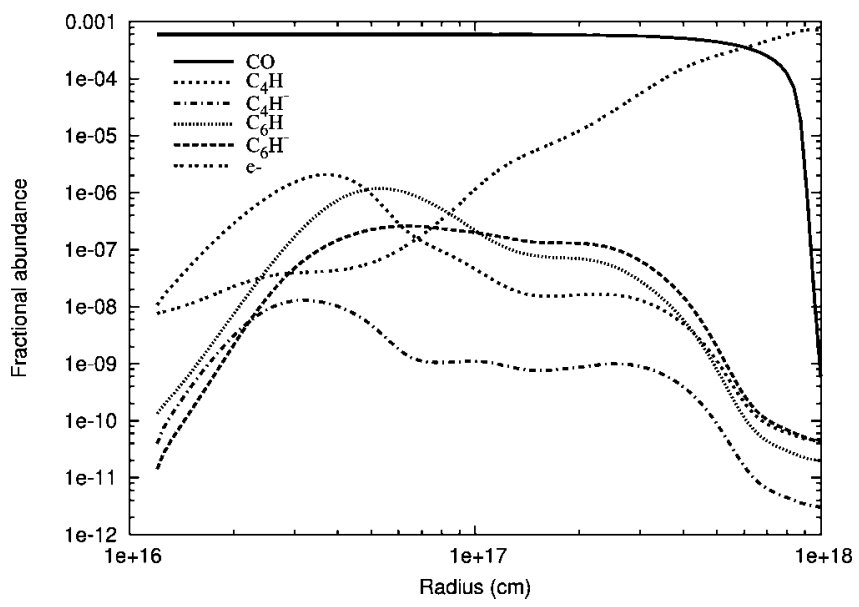

FIG. 1.-IRC + 10216 circumstellar chemistry model results of hydrocarbon and anion abundances (relative to the total number density), calculated as a function of distance from the center of the star. 


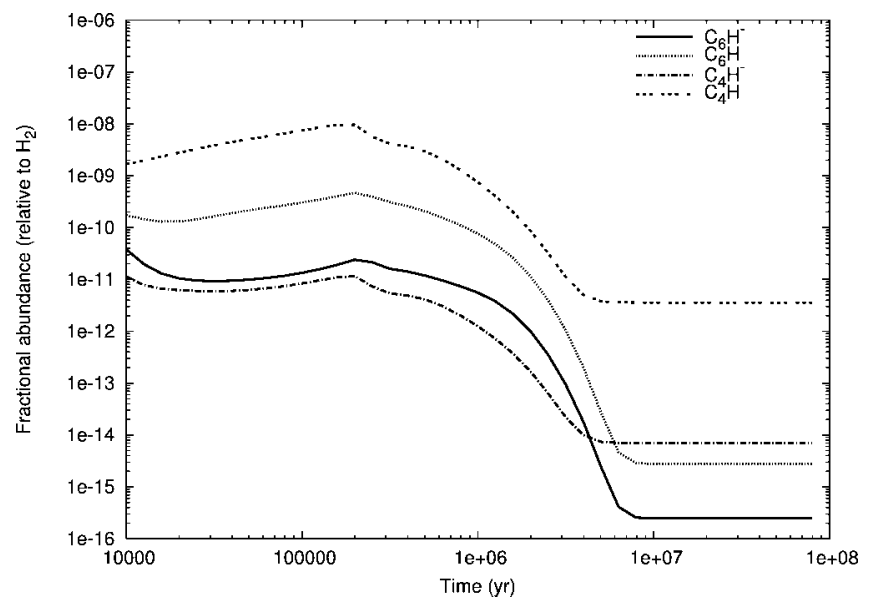

FIG. 2.-TMC-1 dark cloud chemistry model results of hydrocarbon and anion abundances (relative to $\mathrm{H}_{2}$ density), calculated as a function of time.

mental abundances of $\mathrm{C}, \mathrm{N}$, and $\mathrm{O}$ relative to $\mathrm{H}$ are $7.30 \times$ $10^{-5}, 2.14 \times 10^{-5}$, and $1.76 \times 10^{-4}$, respectively. Figure 2 shows the time-dependent evolution of the fractional abundances (with respect to $\mathrm{H}_{2}$ ) of $\mathrm{C}_{4} \mathrm{H}^{-}$and $\mathrm{C}_{6} \mathrm{H}^{-}$and their corresponding neutrals from $10^{4} \mathrm{yr}$, while Tables 3 and 4 present anion column densities and anion/neutral ratios respectively, at both early time $\left(3.16 \times 10^{5} \mathrm{yr}\right)$ and steady state $\left(>10^{8} \mathrm{yr}\right)$. We adopt $N\left(\mathrm{H}_{2}\right)=10^{22} \mathrm{~cm}^{-2}$ in calculating the molecular column densities.

Steady state abundances are very low due to the incorporation of carbon into $\mathrm{CO}$, but much better agreement occurs at earlier times in the evolution. The column density of $\mathrm{C}_{6} \mathrm{H}^{-}$produced in our model at early time $\left(3.16 \times 10^{5} \mathrm{yr}\right), 1.35 \times 10^{11} \mathrm{~cm}^{-2}$, is very close to that observed by McCarthy et al. (2006), $1 \times$ $10^{11} \mathrm{~cm}^{-2}$. We calculate the column density of the neutral $\mathrm{C}_{6} \mathrm{H}$ at early time to be $2.58 \times 10^{12} \mathrm{~cm}^{-2}$, which is in good agreement with the observed value of $4.10 \times 10^{12} \mathrm{~cm}^{-2}$ (Bell et al. 1999). The observed anion-to-neutral ratio is 0.025 , which is in very good agreement with the calculated early-time value of 0.052 , given the uncertainties in assorted rate coefficients.

\subsection{Photon-dominated Regions}

We have used the code developed by the Meudon group (Le Petit et al. 2006) with the additional hydrocarbon chemistry described above. For this model we assume a fixed temperature of $50 \mathrm{~K}$ and parameters representative of those in the Horsehead Nebula; i.e., $G=60 G_{0}$, where $G_{0}$ is the interstellar $\mathrm{UV}$ radiation field, $A_{V}=10$ mag to the cloud center, and a total hydrogen density of $2 \times 10^{4} \mathrm{~cm}^{-3}$. These models are steady state, which

TABLE 3

TMC-1 Hydrocarbon Anion Chemistry Model Results

\begin{tabular}{cccccr}
\hline \hline & \multicolumn{3}{c}{ Column Densities $\left(\mathrm{cm}^{-2}\right)$} & \\
\cline { 2 - 5 } Species & Early Time & Steady State & Observed & Ref. \\
\hline $\mathrm{C}_{4} \mathrm{H} \ldots \ldots \ldots$ & $4.30 \times 10^{13}$ & $3.60 \times 10^{10}$ & $3.4 \times 10^{14}$ & 1 \\
$\mathrm{C}_{4} \mathrm{H}^{-} \ldots \ldots$ & $5.58 \times 10^{10}$ & $6.99 \times 10^{7}$ & $\ldots$ & \\
$\mathrm{C}_{6} \mathrm{H} \ldots \ldots \ldots$ & $2.58 \times 10^{12}$ & $2.78 \times 10^{7}$ & $4.1 \times 10^{12}$ & 2 \\
$\mathrm{C}_{6} \mathrm{H}^{-} \ldots \ldots$ & $1.35 \times 10^{11}$ & $2.47 \times 10^{6}$ & $1.0 \times 10^{11}$ & 3 \\
$\mathrm{C}_{8} \mathrm{H} \ldots \ldots$ & $7.76 \times 10^{11}$ & $1.63 \times 10^{6}$ & $2.2 \times 10^{11}$ & 2 \\
$\mathrm{C}_{8} \mathrm{H}^{-} \ldots \ldots$ & $3.27 \times 10^{10}$ & $6.83 \times 10^{4}$ & $\ldots$ & \\
$\mathrm{C}_{10} \mathrm{H} \ldots \ldots$ & $8.98 \times 10^{10}$ & $3.78 \times 10^{3}$ & $\ldots$ & \\
$\mathrm{C}_{10} \mathrm{H}^{-} \ldots \ldots$ & $3.67 \times 10^{9}$ & $2.05 \times 10^{2}$ & $\ldots$ & \\
\hline
\end{tabular}

References.-(1) Guélin et al. 1982; (2) Bell et al. 1999; (3) McCarthy et al. 2006.
TABLE 4

TMC-1 Hydrocarbon Anion-to-Neutral Ratios $\mathrm{C}_{n} \mathrm{H}^{-} / \mathrm{C}_{n} \mathrm{H}$

\begin{tabular}{cccc}
\hline \hline$n$ & Early Time & Steady State & Observed $^{\text {a }}$ \\
\hline $4 \ldots \ldots$ & $1.30 \times 10^{-3}$ & $1.94 \times 10^{-3}$ & $\ldots$ \\
$6 \ldots \ldots$ & $5.23 \times 10^{-2}$ & $8.91 \times 10^{-2}$ & $2.50 \times 10^{-2}$ \\
$8 \ldots \ldots$ & $4.21 \times 10^{-2}$ & $5.42 \times 10^{-2}$ & $\ldots$ \\
$10 \ldots \ldots$ & $4.10 \times 10^{-2}$ & $5.42 \times 10^{-2}$ & $\ldots$ \\
\hline
\end{tabular}

${ }^{\mathrm{a}}$ McCarthy et al. (2006).

is achieved rapidly due to the enhanced UV field and fast photodestruction rates. The PDR models show that the anionic species formed can survive exposure to a high radiation field present in regions such as the Horsehead Nebula because, given the high electron abundance, the formation path of electron attachment is efficient enough to overcome the rapid photodetachment of the fragile anions. This high electron abundance at low to intermediate extinction can be inferred from the $\mathrm{C}^{+}$abundance in Figure 3, which also shows that significant abundances of the anions arise at low extinction $\left(A_{V} \sim 1.5-3 \mathrm{mag}\right)$. At low $A_{V}$, $\sim 0.5-2 \mathrm{mag}$, the dominant loss of anions is through mutual neutralization with $\mathrm{C}^{+}$(and to a lesser extent through reactions with atomic hydrogen). Thus, since $n\left(\mathrm{C}^{+}\right)=n(e)$ in this region, the anion/neutral abundance ratio depends on the ratio of the rate coefficients for electron attachment and mutual neutralization. For species with more than five carbon atoms, this leads to abundance ratios greater than unity; for smaller species, the ratio is less than 1. In fact, the abundances of the anions are, in some cases, larger than the neutral species. Relevant results are listed in Table 5. Most notably, $\mathrm{C}_{8} \mathrm{H}^{-}$and $\mathrm{C}_{10} \mathrm{H}^{-}$are more dominant than the neutral species with fractional abundances over an order of magnitude greater than those of $\mathrm{C}_{8} \mathrm{H}$ and $\mathrm{C}_{10} \mathrm{H}$.

Since the PDR model provides abundances perpendicular to the line of sight for a PDR seen edge-on, as is the case for the Horsehead Nebula, it is more appropriate to compare fractional abundances rather than column densities. The peak abundance of $\mathrm{C}_{4} \mathrm{H}$ is consistent with observations of the Horsehead region made by Teyssier et al. (2004). Although the relative abundance of $\mathrm{C}_{4} \mathrm{H}^{-}(3.5 \%)$ to its neutral analog is not as high as $\mathrm{C}_{6} \mathrm{H}^{-}$or $\mathrm{C}_{8} \mathrm{H}^{-}$, the higher abundance of the neutral species allows a significantly large absolute value of this anion to be formed. The $\mathrm{C}_{6} \mathrm{H}^{-}$anion has a peak abundance of 4.7 times that of the neutral species. The detection of $\mathrm{C}_{6} \mathrm{H}$ in the Horsehead Nebula was reported by Teyssier et al. (2004), who calculated a peak

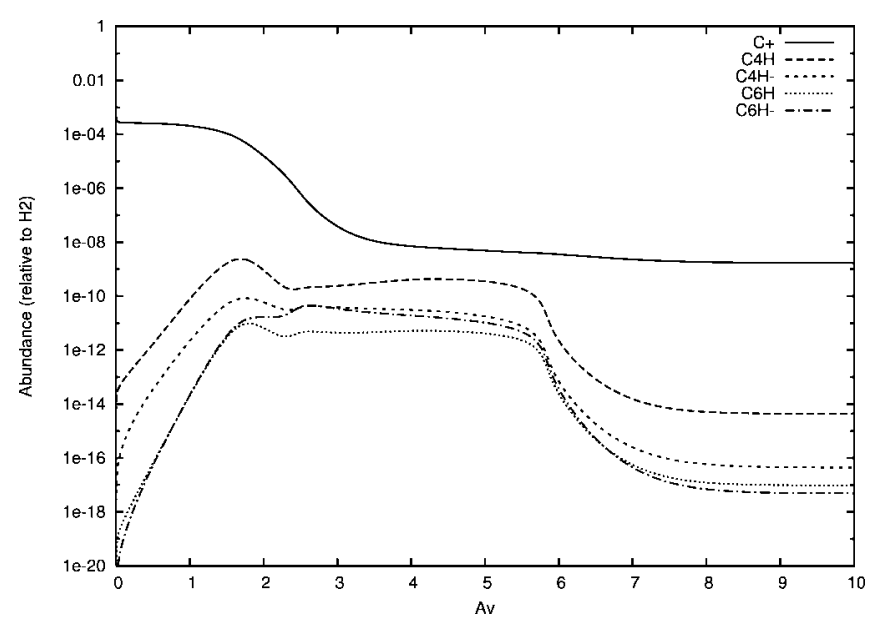

FIG. 3.-Horsehead Nebula PDR chemistry model results of hydrocarbon and anion abundances (relative to $\mathrm{H}_{2}$ ), calculated as a function of $A_{V}$. 
TABLE 5

Horsehead Nebula Hydrocarbon Anion Chemistry MODEl Results

\begin{tabular}{lcc}
\hline \hline Species & $\begin{array}{c}\text { Peak Abundance } \\
\text { relative to } \mathrm{H}_{2}\end{array}$ & $\begin{array}{c}\text { Obs. Peak Abundance } \\
\text { relative to } \mathrm{H}_{2}{ }^{a}\end{array}$ \\
\hline $\mathrm{C}_{4} \mathrm{H} \ldots \ldots \ldots$ & $2.4 \times 10^{-9}$ & $(3.0 \pm 1.2) \times 10^{-9}$ \\
$\mathrm{C}_{4} \mathrm{H}^{-} \ldots \ldots \ldots$ & $8.4 \times 10^{-11}$ & $\ldots$ \\
$\mathrm{C}_{6} \mathrm{H} \ldots \ldots \ldots$ & $9.6 \times 10^{-12}$ & $(1.0 \pm 0.6) \times 10^{-10}$ \\
$\mathrm{C}_{6} \mathrm{H}^{-} \ldots \ldots$ & $4.5 \times 10^{-11}$ & $\ldots$ \\
$\mathrm{C}_{8} \mathrm{H} \ldots \ldots \ldots$ & $5.3 \times 10^{-12}$ & $\ldots$ \\
$\mathrm{C}_{8} \mathrm{H}^{-} \ldots \ldots \ldots$ & $9.3 \times 10^{-11}$ & $\ldots$ \\
$\mathrm{C}_{10} \mathrm{H} \ldots \ldots$ & $3.8 \times 10^{-12}$ & $\ldots$ \\
$\mathrm{C}_{10} \mathrm{H}^{-} \ldots \ldots$ & $5.5 \times 10^{-11}$ & $\ldots$ \\
\hline
\end{tabular}

${ }^{\mathrm{a}}$ Teyssier et al. (2004).

abundance relative to $\mathrm{H}_{2}$ of $1.0 \times 10^{-10}$, about 1 order of magnitude greater than calculated. It is possible that we are missing an important formation mechanism in this environment. One possibility is that hydrocarbon abundances are boosted by destruction of PAH particles, rather than being synthesized from smaller species. In any case, our anion/neutral ratios are independent of the mode of formation of the neutral.

\section{CONCLUSION}

We find that electron attachment to hydrocarbon molecules is very efficient for species containing more than five carbon atoms. The anions are created so efficiently that they can be abundant even in regions where they are destroyed rapidly by photons, such as CSEs and PDRs, and in dark clouds, despite the low fractional abundance of electrons. In particular, we find that anions such as $\mathrm{C}_{6} \mathrm{H}^{-}, \mathrm{C}_{8} \mathrm{H}^{-}$, and $\mathrm{C}_{10} \mathrm{H}^{-}$can have abundances relative to their neutral analogs ranging from a few percent to greater than unity, while $\mathrm{C}_{4} \mathrm{H}^{-}$, although formed relatively inefficiently through electron attachment, can be observable in astronomical objects, given the large column densities of $\mathrm{C}_{4} \mathrm{H}$ detected. In fact, as this Letter was being prepared, we became aware of a paper by Cernicharo et al. (2007) in which the detection of $\mathrm{C}_{4} \mathrm{H}^{-}$in IRC +10216 is reported with a $\mathrm{C}_{4} \mathrm{H}^{-} / \mathrm{C}_{6} \mathrm{H}^{-}$column density ratio of $\frac{1}{7}$, compared to our calculated value of $1 / 17$.

Astrophysics at QUB is supported by a grant from PPARC. R. N. C. and T. J. M. are supported by the European Community's human potential programme under contract MCRTNCT-512302 ("The Molecular Universe"), C. W. by a scholarship from the Northern Ireland Department of Employment and Learning, and M. A. C. by QUB. E. H. acknowledges support for his research program in astrochemistry from the National Science Foundation. We thank Aigen Li for providing us with his code to calculate radiation intensity as a function of wavelength and extinction.

\section{REFERENCES}

Avery, L. W., et al. 1992, ApJS, 83, 363

Barckholtz, C., Snow, T. P., \& Bierbaum, V. M. 2001, ApJ, 547, L171

Bell, M. B., Feldman, P. A., Watson, J. K. G., McCarthy, M. C., Travers, M. J., Gottlieb, C. A., \& Thaddeus, P. 1999, ApJ, 518, 740

Cernicharo, J., Guélin, M., Agúndez, M., Kawaguchi, K., McCarthy, M., \& Thaddeus, P. 2007, A\&A, 467, L37

Dayal, A., \& Bieging, J. H. 1993, ApJ, 407, L37

Eichelberger, B., Barckholtz, C., Stepanovic, M., Bierbaum, V., \& Snow, T. 2002, in NASA Laboratory Astrophysics Workshop, ed. F. Salama (NASA CP-2002-21186; Washington, DC: NASA), 120

Guélin, M., Friberg, P., \& Mezaoui, A. 1982, A\&A, 109, 23

Guélin, M., et al. 1997, A\&A, 317, L1

Gupta, H. C., Brünken, S., Tamassia, F., Gottlieb, C. A., McCarthy, M. C., \& Thaddeus, P. 2007, ApJ, 655, L57

Herbst, E. 1981, Nature, 289, 656

Kawaguchi, K., Kasai, Y., Ishikawa, S.-I., \& Kaifu, N. 1995, PASJ, 47, 853

Le Petit, F., Nehmeé, C., Le Bourlot, J., \& Roueff, E. 2006, ApJS, 164, 506
Lepp, S., \& Dalgarno, A. 1988a, ApJ, 324, 553 1988b, ApJ, 335, 769

Mathis, J. S., Mezger, P. G., \& Panagia, N. 1983, A\&A, 128, 212

McCarthy, M. C., Gottlieb, C. A., Gupta, H. C., \& Thaddeus, P. 2006, ApJ, 652, L141

Millar, T. J. 2003, in Asymptotic Giant Branch Stars, eds. H. J. Habing \& H. Olofsson (New York: Springer), 247

Millar, T. J., Herbst, E., \& Bettens, R. P. A. 2000, MNRAS, 316, 195

Petrie, S. 1996, MNRAS, 281, 137

Petrie, S., \& Herbst, E. 1997, ApJ, 491, 210

Ruffle, D. P., Bettens, R. P. A., Terzieva, R., \& Herbst, E. 1999, ApJ, 523, 678

Terzieva, R., \& Herbst, E. 2000, Int. J. Mass Spectrom., 201, 135

Teyssier, D., Fossé, D., Gerin, M., Pety, J. Abergel, A., \& Roueff, E. 2004, A\&A, 417, 135

Tulej, M., Kirkwood, D. A., Pachkov, M., \& Maier, J. P. 1998, ApJ, 506, L69 Woodin, R., Foster, M. S., \& Beauchamp, J. L. 1980, J. Chem. Phys., 72, 4223 